\title{
HUBUNGAN KOMUNIKASI PEMASARAN DENGAN MINAT MENABUNG NASABAH DI BANK BRI KCP SAMUDERA BANJARMASIN
}

\author{
Muhammad Agus Humaidi \\ Universitas Islam Kalimantan Muhammad Arsyad Al-Banjari Banjarmasin \\ E-mail : m.agus.humaidi@gmail.com
}

\begin{abstract}
ABSTRAK
Penelitian ini bertujuan untuk mengetahui komunikasi pemasaran dan minat menabung nasabah di Bank BRI KCP Samudera Banjarmasin, selain itu untuk mengetahui hubungan komunikasi pemasaran dengan minat nasabah menabung di Bank BRI KCP Samudera Banjarmasin. Metode yang digunakan adalah pendekatan penelitian kuantitatif dan instrumen penelitian dengan kuesioner dianalisis dengan Chi Square Goodness Of Fit dan Pearson Correlation. Hasil penelitian menunjukkan bahwa komunikasi pemasaran pada Bank BRI KCP Samudera Banjarmasin tergolong cukup baik. Sedangkan minat nasabah untuk menabung di Bank BRI KCP Samudera Banjarmasin berada pada kategori baik. Selain itu, terdapat hubungan yang signifikan antara komunikasi pemasaran dengan minat nasabah menabung di Bank BRI KCP Samudera Banjarmasin.
\end{abstract}

Kata Kunci: Komunikasi Pemasaran, Minat Menabung

\section{PENDAHULUAN}

Era globalisasi membuat pelaku bisnis merasa adanya persaingan yang semakin ketat. Salah satu bisnis yang dalam bidang jasa keuangan adalah Bank. Bank merupakan lembaga keuangan yang usaha pokoknya adalah menghimpun dana dari masyarakat dalam bentuk simpanan dan menyalurkan kepada masyarakat dalam bentuk kredit atau bentuk lainnya dalam rangka meningkatkan taraf hidup masyarakat banyak.

Semakin kuatnya tingkat persaingan bisnis dalam sektor perbangkan mendorong para pelaku bisnis menciptakan atau menyediakan produkproduk yang inovatif sehingga dapat memberikan hal yang menarik bagi para pelanggannya, dukungan teknologi menjadi pilihan agar penciptaan produk menjadi bermutu tinggi sehingga pelayanan. Setiap Bank mempunyai bermacam-macam produk yang ditawarkan sesuai dengan kebutuhan nasabahnya sehingga fokus pelaku bisnis akan mengarah pada pertempuran promosi atau berkomunikasi dengan pasar.

Upaya yang dapat dilakukan untuk mempertahankan para nasabah yang sudah ada sekaligus memperkenalkan produk-produk Bank kepada para calon nasabah bisa dilakukan dengan cara komunikasi pemasaran. Komunikasi pemasaran merupakan aktivitas pemasaran yang berusaha menciptakan kesadaran atau pengfetahuan mengenai produk dengan berbagai atributnya, menginformasikan lebih positif, preferensi, dan keinginan membeli produk bersangkutan : Menyebutkan bahwa yang termasuk dalam bentuk komunikasi pemasaran terpadu antara lain periklanan, promosi penjualan, publisitas penjualan perseorangan, hubungan masyarakat dan penjualan langsung, kemasan, sponsorship, dan customer service (morissan, 2007:133).

Menurut Lovelock dan Wright (2005:175) bahwa komunikasi pemasaran memiliki tugas-tugas diantaranya: a) menginformasikan dan mendidik calon nasabah tentang perusahan dan jasa yang ditawarkannya; b) membujuk pasar sasaran bahwa produk jasa tentunya menawarkan solusi terbaik bagi kebutuhan-kebuhan mereka dibandingkan dengan yang ditawarkan perusahan pesaing: c) meninggatkan kembali pelanggan tentang produk tersebut dan memotivasi mereka untuk bertindak; d) memelihara dengan pelanggan yang sudah ada dan memberikan berita terbaru dan informasi lebih lanjut tentang bagaimana mendapatkan hasil terbaik dari produk-produk perusahan tersebut.

Dengan adanya komunikasi pemasaran dalam sebuah perusahaan diharapkan dapat menarik minat masyarakat untuk menabung di Bank. Minat dalam kamus besar bahasa Indonesia diartikan sebagai sebuah kecenderungan hati yang tinggi terhadap suatu gairah atau keinginan (Moeliono, 1999:225). Sedangkan menurut Mappiare (1997:62) minat merupakan suatu perangkap mental yang terdiri dari suatu campuran dari perasaan, harapa, pendirian, prasangka atau kecenderungan lain yang mearahkan individu kepada suatu pilihan tertentu.

Nampaknya antara komunikasi pemasaran dengan minat menabung memiliki hubungan. Hal ini dapat diketahui dari hasil penelitian Sayed A 
Vol 4 No 1 Mei 2021

Azmi (2016) yang menyatakan ada hubungan piositif dan signifikan antara bauran komunikasi pemasaran dengan minat menabung nasabah di Bank Aceh sigli, selain itu dari hasil penelitian Melinda (2009) juga menyatakan bahwa adanya pengaruh antara bauran komunikasi pemasaran terhadap minat menabung di Bank study pada nasabah di Bank BNI Cabang Tuban, serta dari hasil penelitian Novitasari, A Sumarwan (2015) menemukan bahwa komunikasi pemasaran memberikan pengaruh terhadap minat menabung di Bank BJB Syariah.

Bank Rakyat Indonesia atau yang sering dikenal dengan sebutan BRI merupakan salah satu Bank milik pemerintah yang terbesar di Indonesia. Sejak 1 Agustus 1992 berdasarkan Undang-Undang perbangkan No.7 tahun 1992 dan Peraturan Pemerintah RI No.21 tahun 1992 status BRI berubah menjadi perseroan terbatas. Pada tahun 2003 Pemerintah Indonesia memutuskan untuk menjual $30 \%$ saham bank ini, sehingga menjadi perusahaan publik dengan nama resmi PT. Bank Rakyat Indonesia (Persero) Tbk., yang masih digunakan sampai saat ini. BRI memiliki cabang yang tersebar diseluruh Indonesia yang salah satunya ditempatkan di Banjarmasin dengan nama BRI KCP Samudera Banjarmasin. Ada berbagai macam produk-produk yang dikeluarkan oleh BRI diantaranya Simpanan Pelajar (Simpel) BRI, TabunganKU BRI, Tabungan Haji, Tabungan Junio, BritAma, BritAma Valas, BritAma Muda, BritAma Bisnis, BritAma TKI, Simpedes TKI, dan salah satu produk tabungan BRI yang paling terkenal adalah Simpedes.

Fenomena yang terjadi pada Bank BRI KCP Samudera Banjarmasin, tidak sedikit nasabah yang mengungkapkan kritikan dan keluhan karena tidak transparannya dalam memberikan informasi mengenai promo yang di berikan (Andrea, Nasabah Bank BRI KCP Samudera Bnajarmasin 15 April 2019).

Dari permasalah di atas dapat diasumsikan bahwa kemungkinan masalah yang terjadi di Bank BRI KCP Samudera Banjarmasin di sebabkan komunikasi pemasaran yang kurang baik. Apabila diabaikan maka akan mempengaruhi tingkatan minat menabung nasabah yang rendah di Bank BRI KCP Samudera Banjarmasin. Oleh sebab itu peneliti tertarik untuk mengambil judul

"Hubungan Komunikasi Pemasaran dengan Minat Menabung Nasabah di Bank BRI KCP Samudera Banjarmasin".

\section{TINJAUAN PUSTAKA}

\section{Komunikasi Pemasaran}

Komunikasi yang baik akan menumbuhkan rasa loyalitas pelanggan kepada penjual dan akan menciptakan hubungan yang lebih baik antara penjual dengan pelanggannya. Dampak positif yang timbul adalah pelanggan dimaksud akan menjadi volunteer information dan merekomendasi relasinya menjadi pelanggan. Komunikasi efektif tidak hanya dilakukan pada saat frontliner sedang melakukan interaksi dengan pelanggannya, sehingga frontliner harus mampu mengemas perhatian melalui komunikasi yang efektif (Sapri, 2013:63). Menurut Prisgunanto (2006:8) menyatakan komunikasi pemasaran adalah semua-semua elemen promosi dari marketing mix yang melibatkan komunikasi antar organisasi dan target audience pada segala bentuknya dan ditujukan untuk performance pemasaran. Sedangkan Mamang (2013:225) bependapat bahwa komunikasi pemasaran merupakan komunikasi yang dilakukan antara produsen, perantara, pemasaran, dan konsumen, dan merupakan kegiatan untuk membantu konsumen mengambil keputusan di bidang pemasaran serta mengarahkan pertukaran atau transaksi agar lebih memuaskan dengan menyadarkan semua pihak untuk berpikir, berbuat, dan bersikap lebih baik.

Penelitian ini menggunakan pendapat Basu dan Irawan (2000:271-278) untuk mengukur komunikasi pemasaran di Bank BRI KCP Samudera Banjarmasin, antara lain : 1) Periklanan; 2) Promosi penjualan; 3) Publisitas dan 4) Penjualan langsung

\section{Minat}

Minat merupakan suatu rasa lebih suka dan rasa ketertarikan pada suatu hal atau aktivitas, tanpa ada yang menyuruh (Djaali, 2007:121). Selain itu dalam KBBI minat diartikan sebagai kecenderungan hati yang tinggi terhadap sesuatu, gairah, keinginan, dan suka terhadap sesuatu. Sedangkan Kotler (2002:78) mengemukakan bahwa Minat (interest) digambarkan sebagai situasi seseorang sebelum melakukan tindakan, yang dapat dijadikan dasar untuk memprediksi perilaku atau tindakan tersebut. Sedangan menurut Mappiare (1997:62) mengatakan minat merupakan suatu perangkat mental yang terdiri dari suatu campuran dari perasaan, harapan, pendirian perasangka atau kecenderungan lain yang mengarahkan individu kepada suatu pilihan tertentu.

Penelitian ini menggunakan pendapat Crow and Crow dalam Roeuf (2011:31) untuk mengukur minat menabung nasabah di Bank BRI KCP Samudera Banjarmasin, yaitu: 1) Faktor dorongan dari dalam; 2) Faktor motif sosial dan 3) Faktor emosional atau perasaan,

\section{Hubungan Komunikasi Pemasaran dengan Minat}

Salah satu data pendukung yang menurut peneliti perlu dijadikan bagian tersendiri adalah penelitian terdahulu yang relevan dengan permasalahan yang sedang dibahas dalam penelitian ini. Dalam hal ini, fokus penelitian terdahulu yang dijadikan acuan adalah terkait 
Vol 4 No 1 Mei 2021

dengan hubungan komunikasi pemasaran dengan minat. Oleh karena itu, peneliti melakukan langkah kajian terhadap beberapa hasil penelitian berupa jurnal-jurnal melalui internet. Berdasarkan hasilhasil penelitian yang telah dilakukan menyiratkan bahwa variabel komunikasi pemasaran berhubungan dengan minat. Seperti hasil penelitian sebagai berikut: Sayed A Azmi (2016), meneliti tentang Hubungan Bauran Komunikasi Pemasaran Terhadap Minat Menabung Nasabah di Bank Aceh Sigli, berdasarkan nilai koefisien korelasi sebesar 0,423 dan terbukti bahwa Thitung $(4,558)>$ Ttabel 2,00) dengan taraf kepercayaan 95\% sehingga dengan demikian hipotesis yang menyatakan ada hubungan piositif dan signifikan antara bauran komunikasi pemasaran dengan minat menabung nasabah di Bank Aceh sigli dapat diterima.

Selain itu penelitian dari Melinda (2009) tentang Pengaruh Bauran Komunikasi Pemasaran Terhadap Minat Menabung Di Bank Study Pada Nasabah Di Bank Bni Cabang Tuban, berdasarkan analisis dengan kefisien rank spearman ditemukan Rhitung 0,394 sedangkan tabel koefisien nilai krisis koefisien korelasi peringkat speaman pada lampiran (Rtabel) ditemukan nilai 0,195 berdasarkan perbandingan antara Rhitung dengan nilai Rtabel dapat di temukan bahwa Rhitung > Rtabel itu berarti Ha diterima. Serta dari penelitian Novitasari, A Sumarwan (2015) tentang Pengaruh

Komunikasi Pemasaran Terhadap Minat Nasabah Menabung di Bank Jabar Banten Syariah, di peroleh nilai R2 sebesar 0,450 atau $45 \%$ dengan demikian maka komunikasi pemasaran memberikan pengaruh terhadap minat menabung di Bank BJB Syariah secara simultan sebesar $45 \%$ sedangkan sisanya $55 \%$ dipengaruhi faktr lain yang tidak diteliti.

Dari hasil penelitian diatas, maka dapat ditarik kesimpulan bahwa dengan adanya komunikasi pemasaran yang baik maka dapat meningkatkan minat menabung nasabah. Begitu juga sebaliknya, jika komunikasi pemasaran kurang baik maka minat menabung nasabah pun juga akan ikut menurun. Jadi dengan kata lain komunikasi pemasaran akan berhubungan dengan minat menabung.

\section{Kerangka Berfikir}

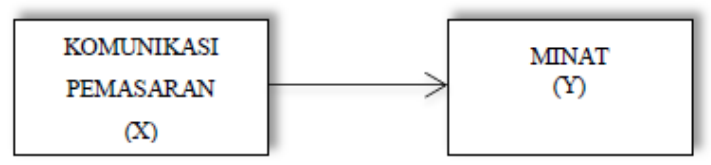

\section{Gambar 2.2. Kerangka Pemikiran Penelitian}

Komunikasi Pemasaran (X) sebagai variabel independen (variabel bebas) mempengaruhi variabel dependen (variabel terikat) Minat Menabung (Y).

\section{Hipotesis}

Hubungan Komunikasi Pemasaran dengan Minat

$\mathrm{HO}$ : Tidak terdapat hubungan signnifikanantara Komunikasi Pemasaran dengan Minat menabung nasabah di Bank BRI KCP Samudera Banjarmasin.

H1 :Terdapat hubungan signifikan antaraKomunikasi Pemasaran dengan Minat menabung nasabah di Bank BRI KCP Samudera Banjarmasin.

\section{METODE PENELITIAN}

\section{Pendekatan Penelitian}

Dalam melakukan penelitian ini penulis memilih jenis penelitian kuantitatif dengan pendekatan survey.

\section{Tipe Penelitian}

Penulis dalam penelitian ini menggunakan metode penelitian deskriptif dan assosiatif.

\section{Lokasi Penelitian}

Penelitian ini dilakukan di Bank BRI KCP Samudera Banjarmasin dengan objek mencakup Hubungan komunikasi pemasaran dengan minat nasabah dalam menabung di Bank BRI KCP Samudera Banjarmasin.

\section{Populasi dan Sampel}

Populasi dalam penelitian ini adalah seluruh nasabah di Bank BRI KCP Samudera Banjarmasin. Dalam penelitian ini populasi tidak diketahui jumlahnya. Menurut Wibisono dalam Riduwan dan Akdon (2013) :

$$
\begin{aligned}
& \mathrm{N}=\left\{\frac{((\mathrm{Za} / 2) \cdot \sigma)}{\mathrm{e}}\right\}^{2} \\
& \mathrm{~N}=\left\{\frac{(1.96 \cdot 0 \cdot 25)}{5 \%}\right\}^{2} \\
& \mathrm{~N}=96,04 \text { dibulatkan } 100
\end{aligned}
$$

Batas kesalahan atau margin of error dalam penelitian ini adalah 5\% (0,05), sehingga tingkat akurasinya sebesar 95\%. Sampel yang diambil untuk mengisi kuesioner sebanyak 100 responden. Skala yang digunakan dalam penelitian ini adalah Skala Likert.

\section{Teknik Pengumpulan Data}

Untuk memperoleh data di Bank BRI KCP Samudera Banjarmasin, khususnya data primer maka dalam penelitian ini digunakan teknik pengumpulan dengan kuesioner (angket).

\section{Definisi Operasional Variabel}

Untuk memperjelas definisi operasional variabel tersebut, peneliti membuat tabel dimana dalam tabel tersebut terdapat bagian kolom variabel, indikator dan parameter. Berikut tabel dapat dilihat dibawah ini : 
MUTAKALLIMIN; Jurnal Ilmu Komunikasi

Vol 4 No 1 Mei 2021 
Tabel 3.2. Definisi Operasional Variabel

\begin{tabular}{|c|c|c|}
\hline Variabel & Indikator & \\
\hline \multirow{4}{*}{$\begin{array}{l}\text { Komunikasi Pemasaran } \\
\text { merupakan komunikasi } \\
\text { antara produsen, perantara, } \\
\text { pemasaran dan konsumen } \\
\text { dimana bagian dari } \\
\text { pemesaran berusaha } \\
\text { menginformasikan, } \\
\text { membujuk dan mengingatkan } \\
\text { konsumen tentang produk } \\
\text { yang mereka jual. }\end{array}$} & Periklanan & $\begin{array}{l}\text { - Media ik } \\
\text { - Frekuens }\end{array}$ \\
\hline & Promosi & $\begin{array}{l}\text { - Promosi } \\
\text { - Promosi }\end{array}$ \\
\hline & Publisitas & $\begin{array}{l}\text { - Citra Bai } \\
\text { - Kegiatan }\end{array}$ \\
\hline & Penjualan langsung & $\begin{array}{l}\text { - Kemamp } \\
\text { - Penampi }\end{array}$ \\
\hline \multirow{3}{*}{$\begin{array}{l}\text { Minat merupakan suatu } \\
\text { perasaan seseorang yang } \\
\text { menyatakan rasa suka dan } \\
\text { tertarik untuk bertindak dan } \\
\text { bertingkah laku terhadap } \\
\text { obyek yang menarik } \\
\text { perhatiannya sehingga } \\
\text { mengarah kepada suatu } \\
\text { pilihan tertentu }\end{array}$} & Dorongan dari dalam & $\begin{array}{l}\text { - Rendahn } \\
\text { awal. } \\
\text { - Untuk ke } \\
\text { - Agar uan }\end{array}$ \\
\hline & Motif sosial & $\begin{array}{l}\text { - Karena a } \\
\text { - Karena il }\end{array}$ \\
\hline & Emosional/Perasaan & $\begin{array}{l}\text { - Pempros } \\
\text { - Kemudal } \\
\text { - Jalinan R }\end{array}$ \\
\hline
\end{tabular}

\section{Analisa Data}

Untuk menjawab rumusan masalah pertama maupun kedua, sekaligus menjawab hipotesis komunikasi pemasaran dan minat menabung nasabah dalam penelitian ini menggunakan rumus Chi Square Goodness Of Fit. Sedangkan untuk menjawab rumusan masalah ketiga mengenai hubungan variabel $\mathrm{X}$ dengan variabel Y digunakan statistik Korelasi Pearson.

\section{HASIL PENELITIAN DAN PEMBAHASAN} 1. Komunikasi Pemasaran

Tabel 4.22. Komunikasi Pemasaran

\begin{tabular}{|c|c|c|c|}
\hline No. & Keterangan & $\mathbf{F}$ & $\%$ \\
\hline 1. & Sangat Baik & 5 & 5,0 \\
\hline 2. & Baik & 21 & 21.0 \\
\hline 3. & Cukup Baik & 46 & 46.0 \\
\hline 4. & Kurang Baik & 11 & 11,0 \\
\hline 5. & Tidak Baik & 17 & 17,0 \\
\hline \multicolumn{2}{|r|}{ Jumlah } & 100 & 100,0 \\
\hline
\end{tabular}

Dari tabel 4.22. tersebut, ternyata kesimpulan disemua kategori komunikasi pemasaran di Bank BRI KCP Samudera Banjarmasin, menunjukan bahwa komunikasi pemasaran di Bank BRI KCP Samudera Banjarmasin Cukup Baik.

\section{Kinerja Pegawai}

Tabel 4.23. Minat Menabung

\begin{tabular}{clcc}
\hline No. & Keterangan & F & \%, \\
\hline 1. & Sangat Baik & 31 & 31,0 \\
2. & Baik & 50 & 50,0 \\
3. & Cukup Baik & 14 & 14,0 \\
4. & Kurang Baik & 4 & 4,0 \\
5. & Tidak Baik & 1 & 1,0 \\
\hline & Jumlah & 100 & 100,0 \\
\hline
\end{tabular}

Sumber: Analisa Data Primer 2019

Dari tabel 4.23. tersebut, ternyata kesimpulan disemua kategori minat menabung nasabah di Bank BRI KCP Samudera Banjarmasin, menunjukan bahwa minat menabung nasabah di Bank BRI KCP Samudera Banjarmasin Baik.

\section{Hubungan Komunikasi Pemasaran dengan Minat Menabung}

Tabel 4.24. Hubungan Komunikasi Pemasaran dengan Minat Menabung

\section{Correlations}

\begin{tabular}{llrr} 
& \multicolumn{1}{c}{$\mathrm{X}$} & \multicolumn{1}{c}{$\mathrm{Y}$} \\
\hline $\mathrm{X}$ & Pearson Correlation & 1 & $.387^{*-}$ \\
\cline { 2 - 4 } & Sig. (2-tailed) & & .000 \\
\cline { 2 - 4 } $\mathrm{N}$ & 100 & 100 \\
\hline $\mathrm{Y}$ & Pearson Correlation & $.387^{-*}$ & 1 \\
\cline { 2 - 4 } & Sig. (2-tailed) & .000 & \\
\hline $\mathrm{N}$ & 100 & 100 \\
\hline
\end{tabular}

* . Correlation is significant at the 0.01 level (2tailed).

Pada tabel di atas terlihat bahwa nilai korelasi antara komunikasi pemasaran dengan minat menabung nasabah mempunyai nilai korelasi 0,387 dan nilai probabilitas 0,000. Berdasarkan nilai korelasi 0,387 menunjukan terdapat hubungan atau korelasi antara komunikasi pemasaran dengan minat, korelasi tersebut mempunyai sifat hubungan Rendah. Hasil probabilitas menunjukan bahwa $0,000<0,05$, hal ini menunjukan bahwa $\mathrm{H} 0$ ditolak, dengan demikian hipotesis H1 yang menyatakan terdapat hubungan signifikan antara komunikasi pemasaran dengan minat menabung nasabah di Bank BRI KCP Samudera Banjarmasin diterima. Jadi dapat disimpulkan bahwa apabila komunikasi pemasaran membaik maka minat menabung nasabah pun ikut membaik, demikian pula sebaliknya bila komunikasi pemasaran kurang baik maka minat menabung nasabah pun akan kurang baik.

\section{PENUTUP}

\section{Kesimpulan}

Berdasarkan hasil analisis tentang hubungan komunikasi pemasaran dengan minat menabung 


\section{MUTAKALLIMIN; Jurnal Ilmu Komunikasi}

Vol 4 No 1 Mei 2021

nasabah di Bank BRI KCP Samudera Banjarmasin maka dapat disimpulkan sebagai berikut:

1) Komunikasi pemasaran pada Bank BRI KCP Samudera Banjarmasin, yang termasuk kategori Cukup Baik. Sebanyak 46 orang $(46,0 \%)$, sedangkan yang kategori Baik sebanyak 21 orang $(21,0 \%)$, kategori Tidak Baik 17 orang $(17,0 \%)$, sedangkan yang kategori Kurang Baik sebanyak 11 orang $(11,0 \%)$ dan hanya 5 orang $(5,0 \%)$ yang termasuk kategori Sangat Baik. Hal ini menunjukan bahwa komunikasi pemasaran pada Bank BRI KCP Samudera Banjarmasin Cukup Baik.

2) Minat menabung pada Bank BRI KCP Samudera Banjarmasin, yang termasuk dalam kategori Baik sebanyak 31 orang $(31,0 \%)$, sedangkan kategori Sangat Baik sebanyak 31 orang $(31,0 \%)$, kategori Cukup Baik 14 orang $(14,0 \%)$, serta kategori Kurang Baik sebanyak 4 orang $(4,0 \%)$, dan ada 1 orang $(1,0 \%)$ yang termasuk kategori Tidak Baik. Hal ini menunjukan bahwa minat menabung nasabah pada Bank BRI KCP Samudera Banjarmasin Baik.

3) Komunikasi pemasaran dengan minat menabung nasabah mempunyai nilai korelasi 0,387 dan nilai probabilitas 0,000 . Berdasarkan nilai korelasi 0,387 menunjukan terdapat hubungan atau korelasi antara komunikasi pemasaran dengan minat, korelasi tersebut mempunyai sifat hubungan Rendah. Hasil probabilitas menunjukan bahwa $0,000<0,05$, hal ini menunjukan bahwa H0 ditolak, dengan demikian hipotesis $\mathrm{H} 1$ yang menyatakan terdapat hubungan signifikan antara komunikasi pemasaran dengan minat menabung nasabah

\section{DAFTAR PUSTAKA \\ 1. Buku}

Basu Swastha dan Irawan. 2000. Manajemen Pemasaran Modern. Edisi 2. Yogyakarta : Liberty.

Boediono. 1985. Ekonomi Moneter:

Pengantar Ilmu Ekonomi No.5.

Yogyakarta: BPFE.

Chaplin. 1989. Kamus Lengkap Psychology. Jakarta: CV Rajawali.

Djaali. 2007. Psikologi Pendidikan. Jakarta:

Bumi Aksara.

Ghozali, Imam. 2005. Aplikasi Analisis

Multivariate dengan SPSS.

Semarang: Badan Penerbit UNDIP. di Bank BRI KCP Samudera Banjarmasin diterima.

\section{Saran}

Dari kesimpulan yang telah dikemukakan berdasarkan hasil analisis yang diperoleh maka ada beberapa saran-saran yang perlu dijadikan pertimbangan yaitu:

1) Berdasarkan hasil analisis tingkat komunikasi pemasaran berada pada kategori Cukup Baik. Hal ini menandakan karyawan dalam memasarkan produknya cukup baik bagi nasabah. Oleh karena itu hendaklah Bank BRI KCP Samudera Banjarmasin agar terus meningkatkan komunikasi pemasarannya.

2) Berdasarkan hasil analisis tingkat minat menabung nasabah termasuk pada kategori Baik. Hal ini menandakan minat nasabah untuk menabung di Bank BRI KCP Samudera Banjarmasin cukup disukai nasabahnya. Oleh karena itu, diharapkan Bank BRI KCP Samudera Banjarmasin agar terus dapat mempetahankannya dan lebih baik lagi apabila minat menabung nasabah di Bank BRI KCP Samudera Banjarmasin ditingkatkan.

3) Dengan adanya hubungan antara komunikasi pemasaran dengan minat menabung, hendaknya seluruh karyawan di Bank BRI KCP Samudera Banjarmasin terus meningkatkan komunikasi pemasaran dalam melayani nasabahnya, agar minat menabung nasabah di Bank BRI KCP Samudera Banjarmasin lebih banyak peminatnya.

Ilham. Prisgunanto. 2006.

Komunikasi Pemasran, Strategi, dan Taktik. Jakarta: Ghalia Indonesia.

Kartika, Erna. 2008. Analisis Faktor

Eksternal yang Mempengaruhi

Keputusan Membeli Mobil Toyota

Avanza dan Daihatsu Xenia Kartika.

<http.repository.usu.ac.id/bitstream

123456789/4308/1/09E00155.pdf>,

Diakses pada 28 Mei 2019.

Kotler, Philip and Kevin Lane Keller. 2016.

Marketing Management. Edisi 15.

New Jersey: Prentice-Hall 
MUTAKALLIMIN; Jurnal Ilmu Komunikasi

Vol 4 No 1 Mei 2021

Published.

Lovelock dan Wright. 2005. Manajemen

Pemasaran Jasa. Indonesia :

Kelompok Gramedia Indeks

Mangkunegara, A.A. Anwar Prabu. 2002.

Perilaku Konsumen. Edisi revisi.

Bandung: PT. Refika Aditama.

Mappiare. A. 1997.Psikologi Remaja.

Surabaya: Usaha Nasional

Morissan. 2007. Periklanan Dan

Komunikasi Pemasaran Terpadu.

Tangerang : Ramdina Prakarsa

Nasution. 2005. Manajemen Mutu Terpadu:

Total Quality Management. Bogor:

Ghalia Indonesia.

Rouf, Abdul. 2011. “Analisis Faktor

Faktor Yang mempengaruhi minat

Masyarakat Membayar Zakat Di

Rumah Zakat Cabang Semarang".

Skripsi. Diterbitkan. Semarang:

IAIN Walisongo Fakultas Syariah.

Sugiyono. 2012. Metode Penelitian

Pendidikan (Pendekatan Kuantitatif,

Kualitatif dan $R \& D)$. Bandung:

ALFABETA.

Winardi. 1995. Pengantar Ilmu Ekonomi:

Buku 1. Edisi VII. Bandung: Tarsito.

\section{Skipsi}

Arlinda Novitasari Sumarwan. 2015.

Pengaruh Komunikasi Pemasaran terhadap Minat Nasabah Menabung

di Bank Jabar Banten Syariah (Bank $B J B)$. Skripsi. Universitas Islam Bandung

Melinda. 2009. Pengaruh Bauran

Komunikasi Pemasaran terhadap

Minat Menabung di Bank (Studi

Pada Nasabah di Bank BNI Cabang

Tuban). Skripsi. Universitas Gadjah

Mada

Sayed Azrul Azmi. 2016. Hubungan Bauran

Komunikasi Pemasaran terhadap

Minat Menabung Nasabah di Bank

Aceh Sigli. Skripsi. Universitas

Syiah Kuala Banda 